\title{
Impact of House Environmental Conditions on people's Adaptation to Quarantine during Corona
}

\author{
Seyede Fereshteh Ehsani Oskouei ${ }^{1}$, Zinat Aminifar ${ }^{1}$, Jamal-E-Din Mahdinejad ${ }^{1 *}$, Hamidreza Azemati $^{1}$ \\ 1. Faculty of Architecture \& Urban Design, Shahid Rajaee Teacher Training University, Tehran, Iran
}

Received: 20 April 2021

Accepted for publication: 21 Nomeber 2021

[EPub a head of print-18 December 2021]

Payesh: 2021; 20 (6): $759-771$

\begin{abstract}
Objective (s): This research aimed to identify residential environment's characteristics, which are important how to adapt to new quarantine lifestyle.

Methods: This was a cross section study. A sample of 813 individuals answered to an online questionnaire distributed on social media. The data were analyzed based on descriptive statistics, and a machine learning method named decision tree model.

Results: Most of changes made by the residents have been applied in bedroom, living room, reception room, balcony and entrances. The satisfaction with the responsibility of house to quarantine conditions, used spaces and activities performed during the quarantine, color variety and the predominant color of the house, the possibility of exercising at house, and the type of house during the quarantine period were the most important characteristics that contributed to residents' adaptability with quarantine.

Conclusion: House environmental conditions affect the level of adaptation of people to quarantine. Flexible living environments that might allow the residents to interact with each other could be more successful in helping people to adapt with confinement. In order to improve the adaption, the possibility of exercising at house, communication with nature and smart use of colors in indoor spaces and household density should be receive more attention.
\end{abstract}

Keywords: House, Residential Environment, Adaption, Quarantine, Corona Pandemic.

\footnotetext{
${ }^{*}$ Corresponding author: Faculty of Architecture \& Urban Design, Shahid Rajaee Teacher Training University, Tehran, Iran

E-mail: mahdinejad@sru.ac.ir
} 


\title{
تأثير شرايط محيطى مسكن بر ميزان ساز كارى افراد با قرنطينه در دوران كرونا
}

\author{
سيده فرشته احسانى اسكويى' ‘ زينت امينى فر ' جمال الدين مهدىنزاد '، حميدرضا عظمتى '
}

1. دانشكده معمارى و شهرسازى، دانشگاه تربيت دبير شهيد رجايى، تهران، ايران

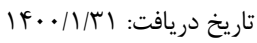

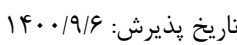

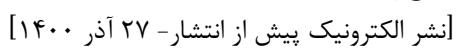

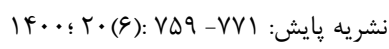

جكيده مقدمه: همه گيرى ويروس كرونا و قرنطينه خانگى ناشى از آن، سبك زندگى جديدى را در جامعه يديد آورده است. هدف اين يزوهش، شناسايى آن دسـته

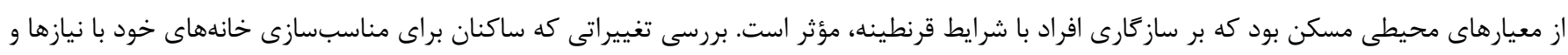

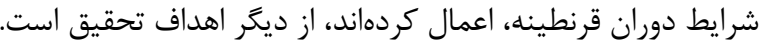

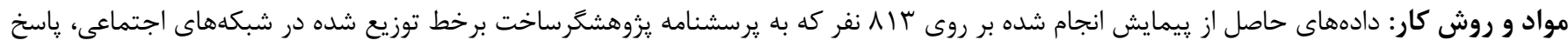

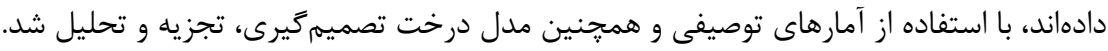

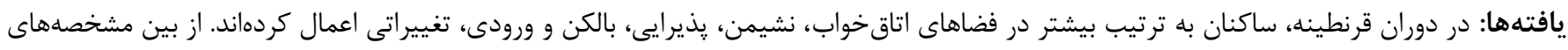

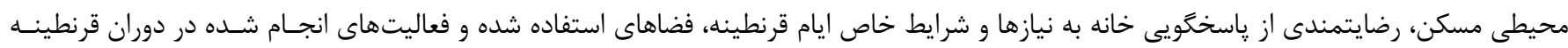

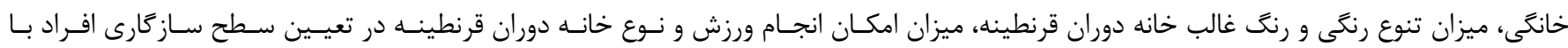
خانهنشينى، نقش بيشترى داشته است.

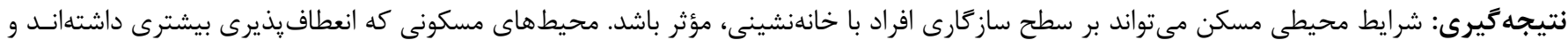

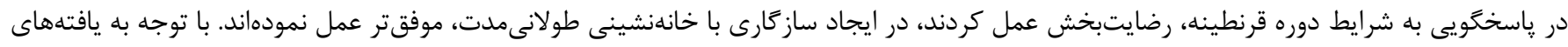

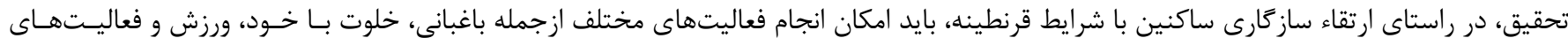

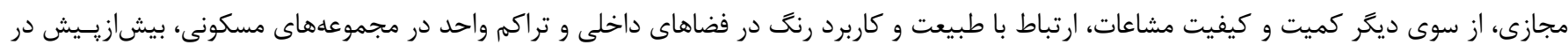
طراحى مسكن مورد توجه قرار كيرد.

كليد وازه ها: مسكن، محيط سكونتى، ساز گارى، قرنطينه، همدكيرى كرونا 


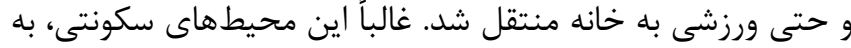

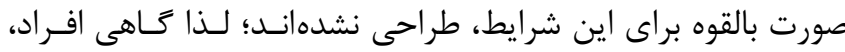

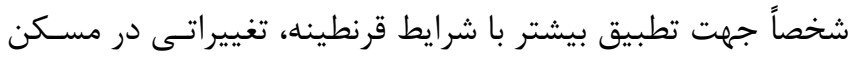

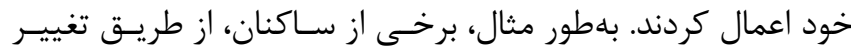

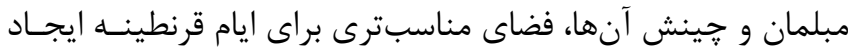

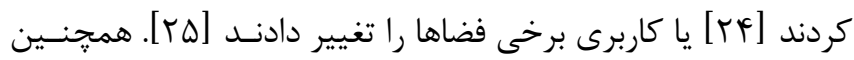

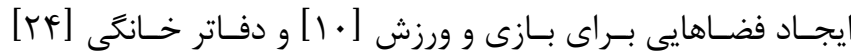
كوجى از ديخر اقدامات اين افراد بوده است.

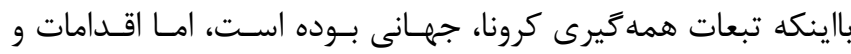

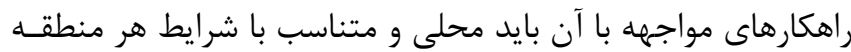

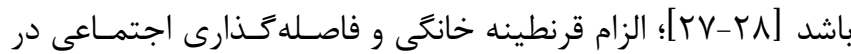

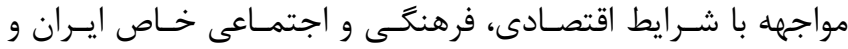

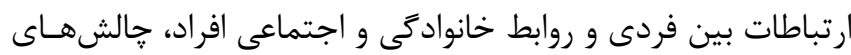

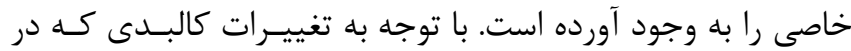

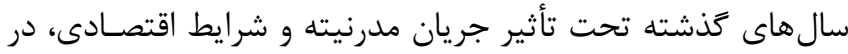
مسكن ايران به وجود آمده و ازآنجايى كه احتمال دارد مواردى شبيد مديه

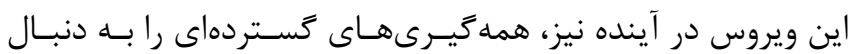

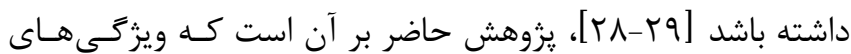

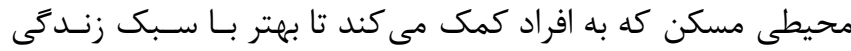
قرنطينه سازكار شوند يا تغييراتى كه ساكنان براى تطبيق خانه هاى

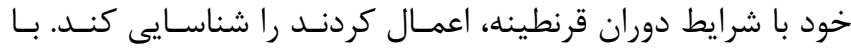
دخيل كردن نتايج اين يزوهش در امر برنامهريزى و طراحى مسكن،

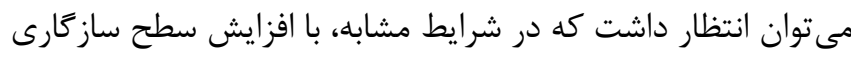

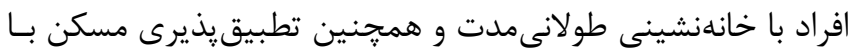

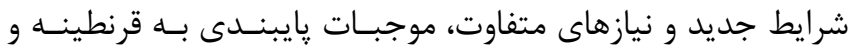

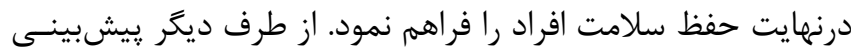

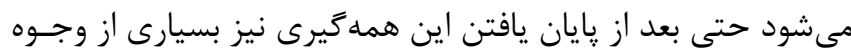

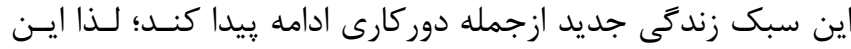

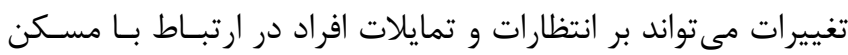

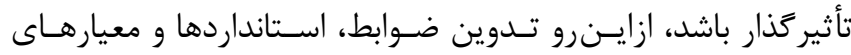
طراحى مسكن بايد با هوشيارى كامل نسبت به اين مسائل باشد. سؤالات اصلى تحقيق از اين قرار بودند:

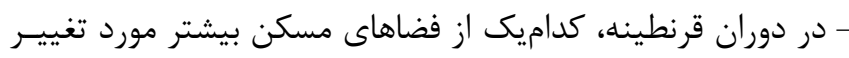
و تحول عملكردى يا كالبدى قرار گرفته است؟ درنط

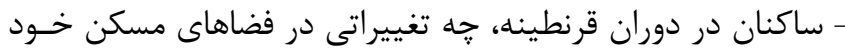

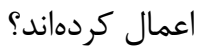

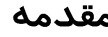

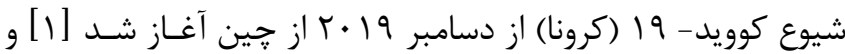
به سرعت كشـورهاى زيـادى را درگيــر كـرد. در حسال حاضـر، ايـن

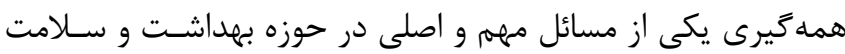

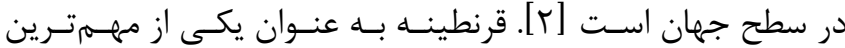

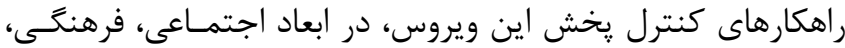

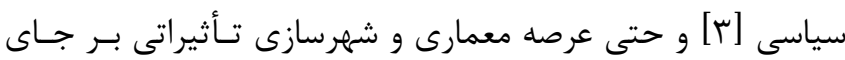

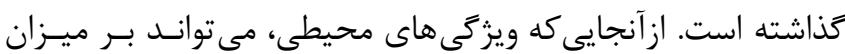

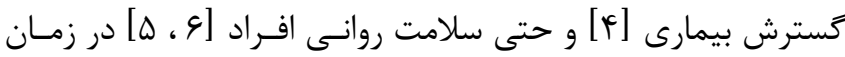

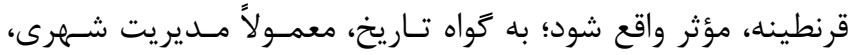

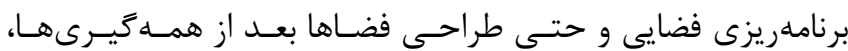

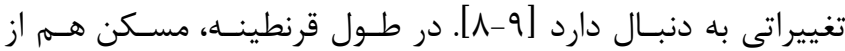

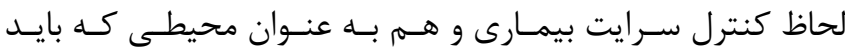

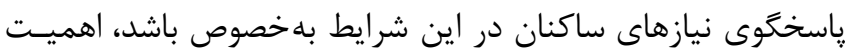

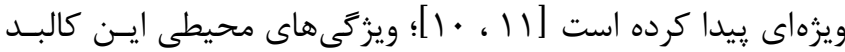

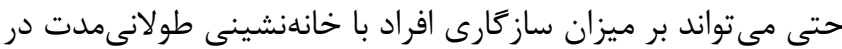

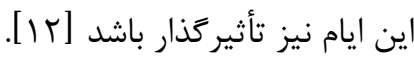
يزوهشها نشان مى دهد در زمان قرنطينه، نخر انىهاى افراد در مورد

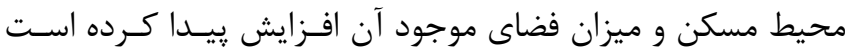

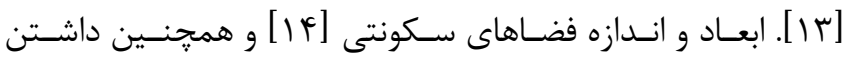

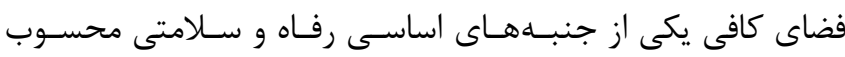

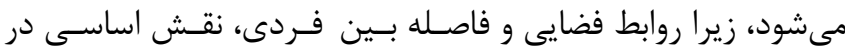

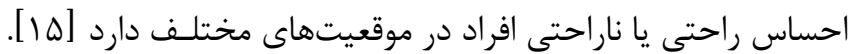

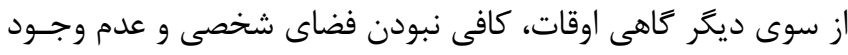

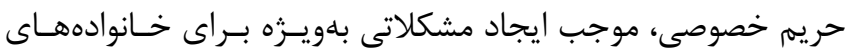

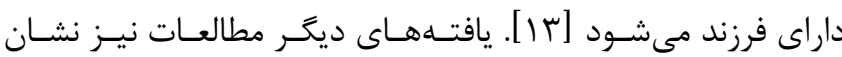

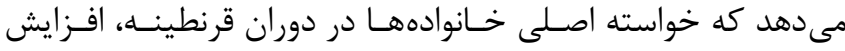

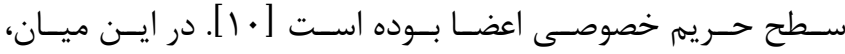

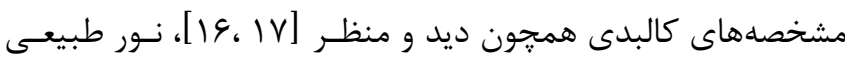

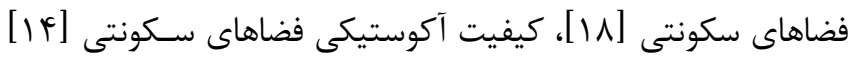

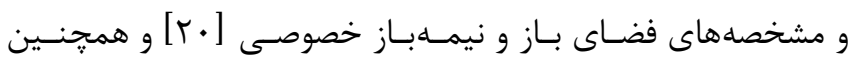

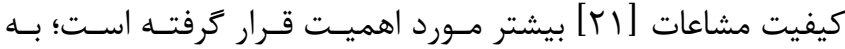

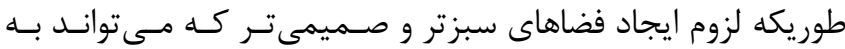

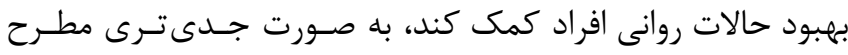

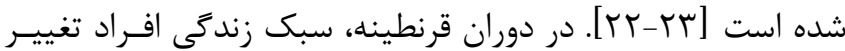
كرد و بهناجار انجام بسيارى از فعاليتهاى كارى، آموزشى، تفريحى فرئه 
نزديك به همان جيزى باشد كه فـرد بـــراى نيازهـا و آرمـانهـايش

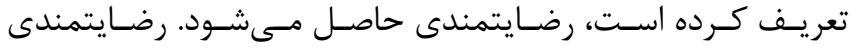

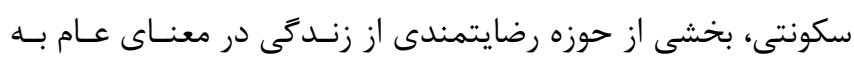

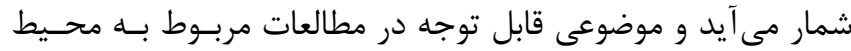

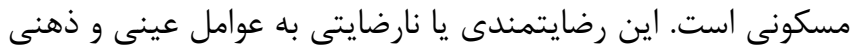

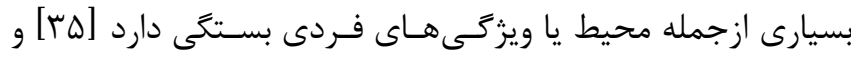
مىتواند بر سازكارى افراد با قرنطينه نيز تأثير كذار باشد [ـ [1]

\section{مواد و روش كار}

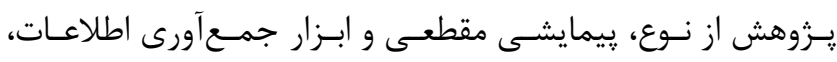

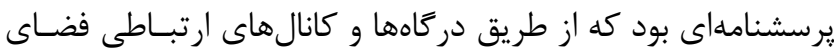

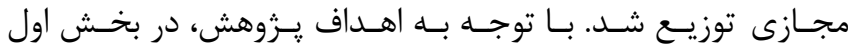
يرسشنامه، سؤالاتى در مورد مشخصات فردى شامل جنسيت، گَروه

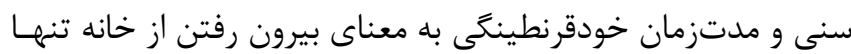

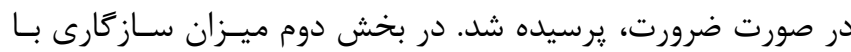

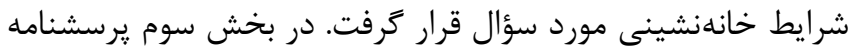

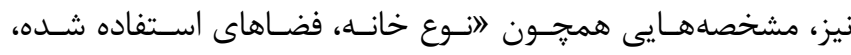
فعاليتهاى انجام شده در زمان قرنطينه، مساحت خانه، تراكم واحـــ

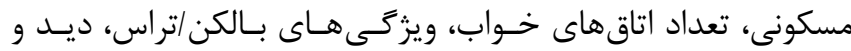

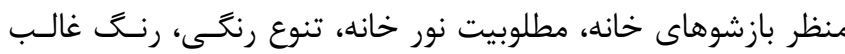

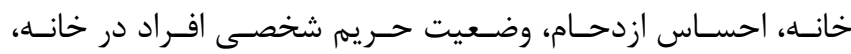

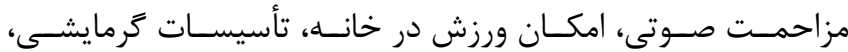

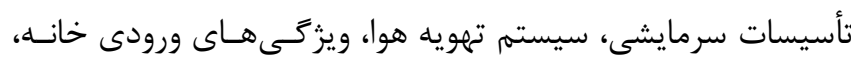

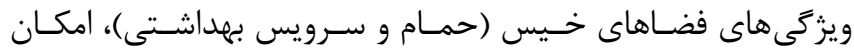

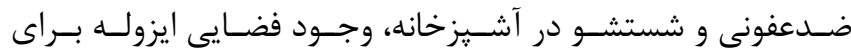

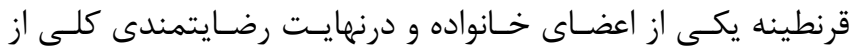

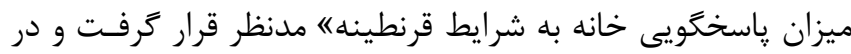

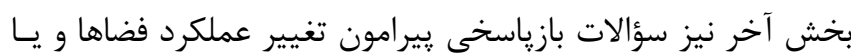

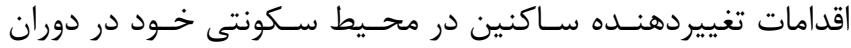

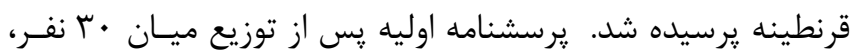

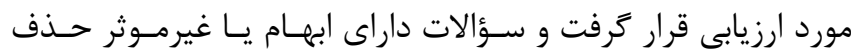
كرديدند و نسخه ويرايش شده يرسشنامه در مرداد و شهريور

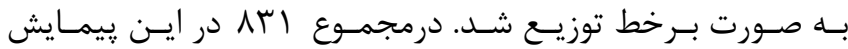

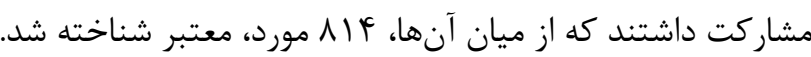

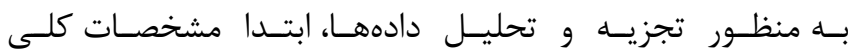

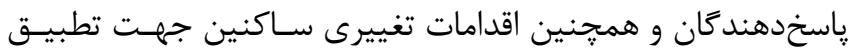

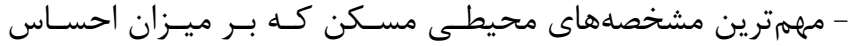

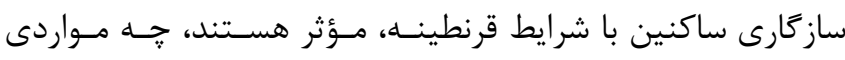
هستند؟ سارك

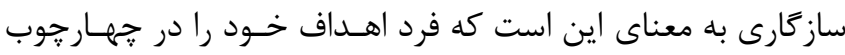

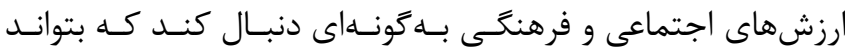

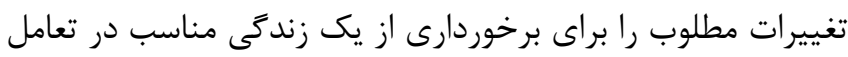

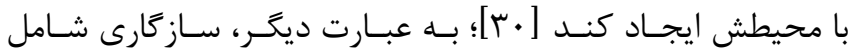
اقدامات و فرآيندهايى است كه مردم انجام مى دهند تا بين محيط و

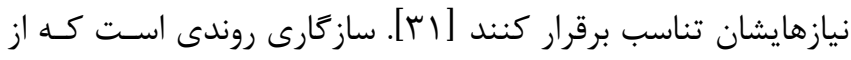

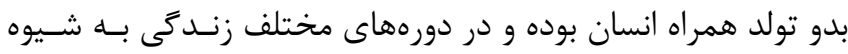
خاص تحقق مىيابد. ساز كارى با محيط يك ضرورت دان حياتى به شمار

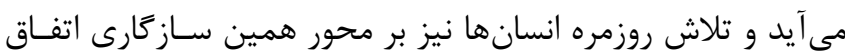

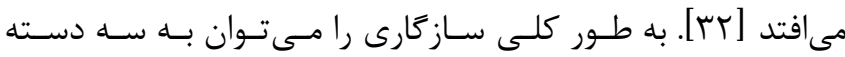

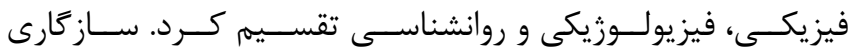

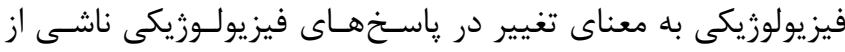

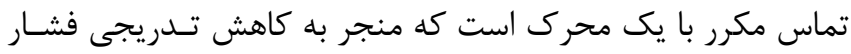

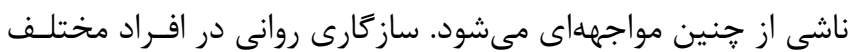

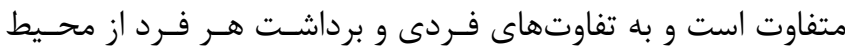
بازمى كردد. بهطور مثال زمان قرار ترفتن افراد در يك شرايط خاص

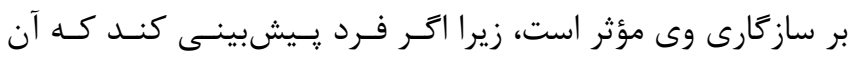
وضعيت كوتاهمدت است، در معرض احساسات منفى قرار نمى خئريـرد

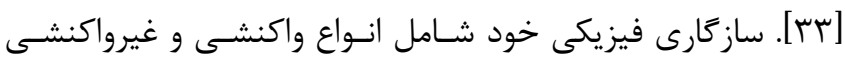

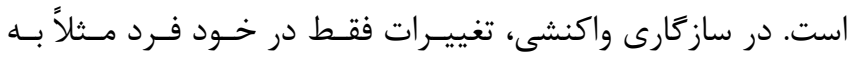

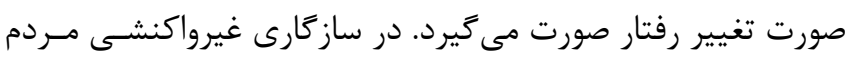

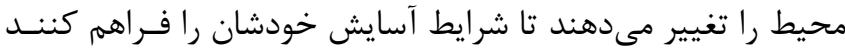

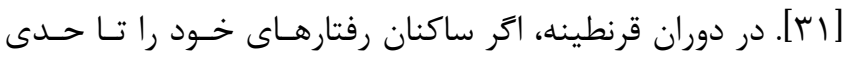

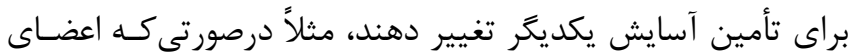

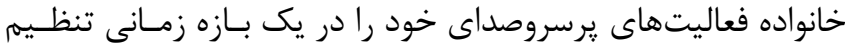

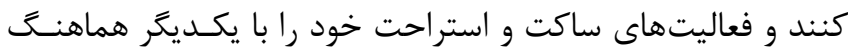

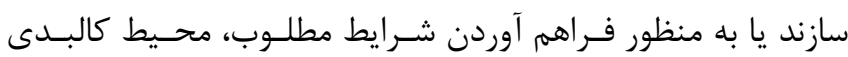

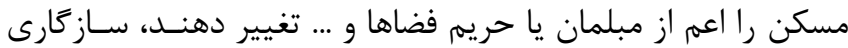

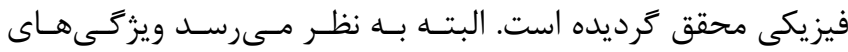

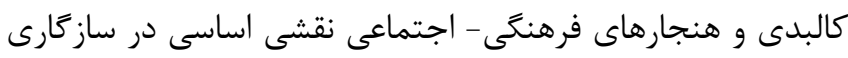

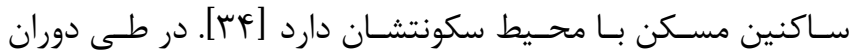

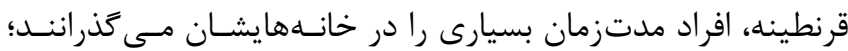

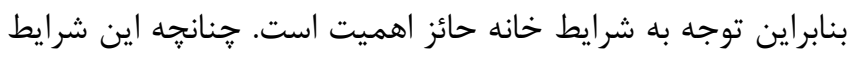


بيش از نيمى از افراد به سؤال بازياسخ يرسشـنامه مبنـى بــر تغييـر

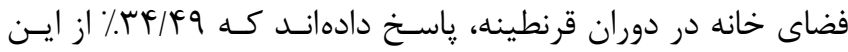

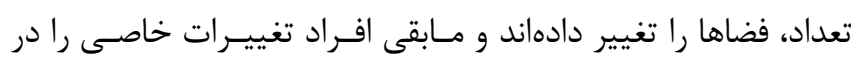

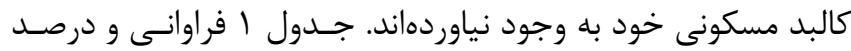

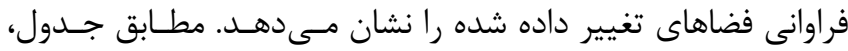

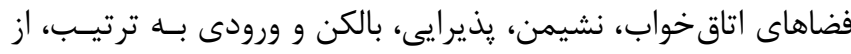

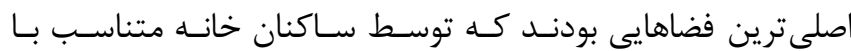
نيازهاى جديدشان تغيير داده شدهاند.

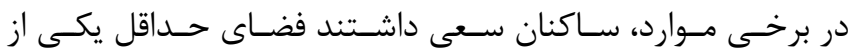
اتاقخوابها را براى دور كارى يا تحصيل مجازى مناسبسازى كنيند؛ دارئ اين امر غالباً با اضافه كردن ميز مطالعه و كامييوتر و قوفسه نكَهدارى

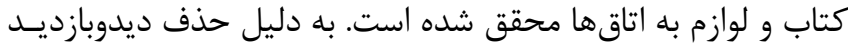

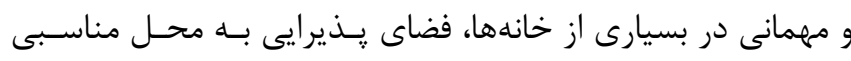

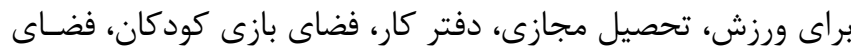

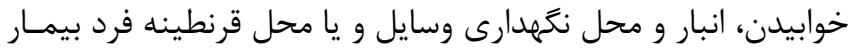
تبديل شده است. نشيمن علاوه بر كاركرد اصلى خـود عملكردهـاى

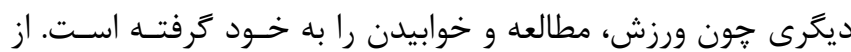

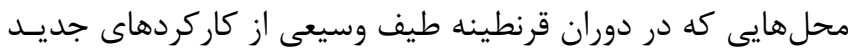
را به خود اختصاص داده، بالكن است. در اين دوران، بالكن به محلى دالى دانى

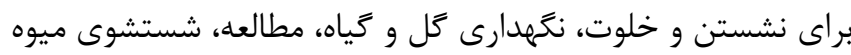
و سبزى، ضدعفونى كردن لوازم يا نكَهــدارى وسـايلى كـهـ از بيــرون منزل وارد شدهاند، نكمهدارى لباس ها، كيف و وسـايل آلـوده تبـديل

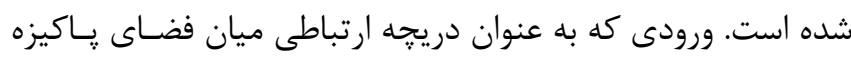

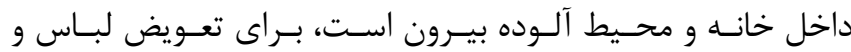

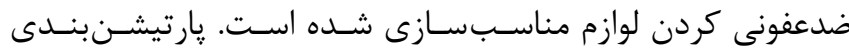

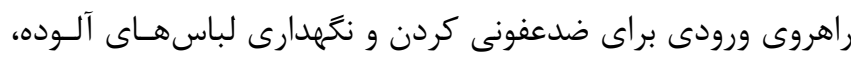

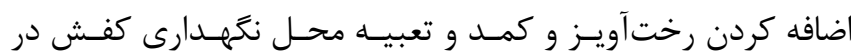
بيرون از منزل ازجمله اقدامات سطحى و سـريع در ايسن قسـمت از

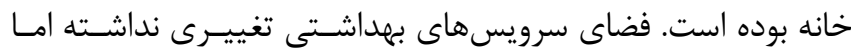

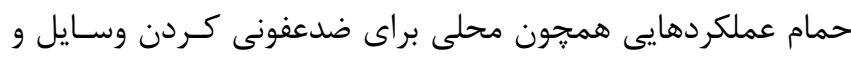

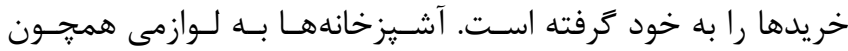
يخجال و ظرفشويى اضافى تجهيز شدند تا نكهدارى مواد غذايى در

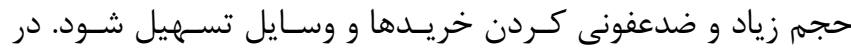
برخى موارد از ميز ناهارخورى به عنوان ميز كارن خرار، محل انجام تكاليف مدرسه، محل قرار دادن كامييوتر و ميز مطالعه استفاده شده اسـت.

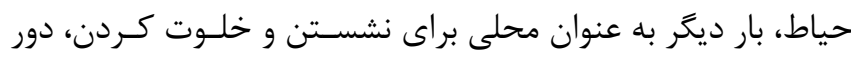

با شرايط جديد براساس آمار توصيفى مورد بررسى قرار كرفته است؛ سيس براى تشخيص مهممترين فاكتورهاى شرايط محيطى مسكـن

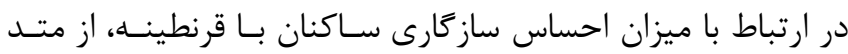

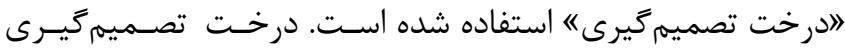
يكى از مدلهاى رايج در دادهاوى است كه تاكنون در اغلب مسائل

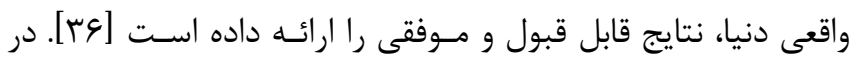
اين درخت، هر كره نمايانكر يك مشخصه و هر شاخه كه از آن كَره

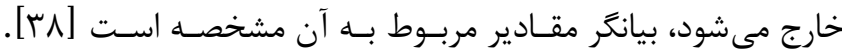

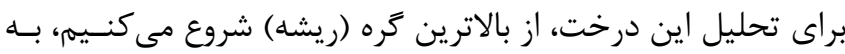

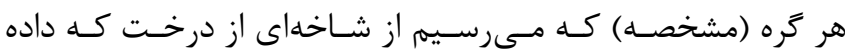

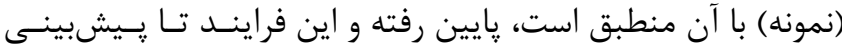
متغير وابسته ادامه مىيابد.

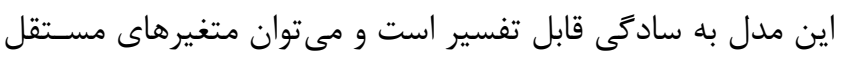

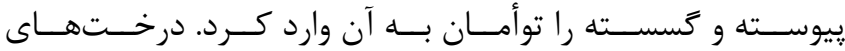

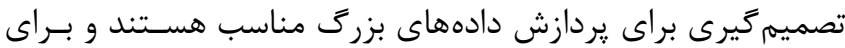

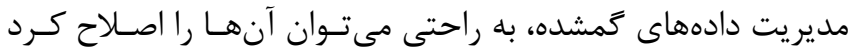

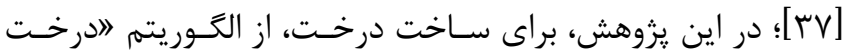

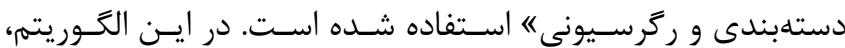

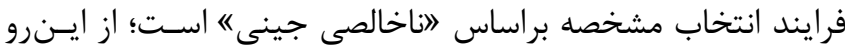

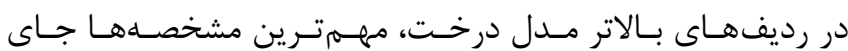

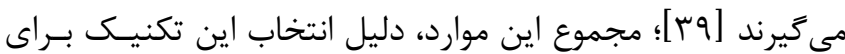

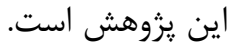

يافتهها

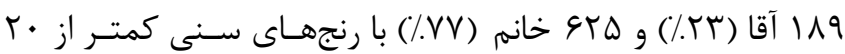

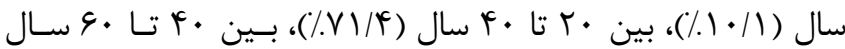

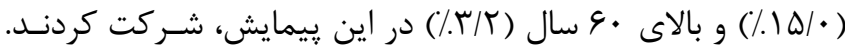

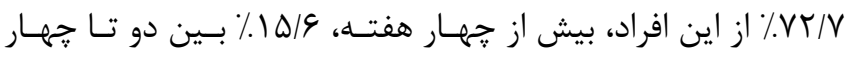

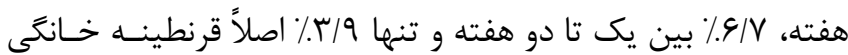

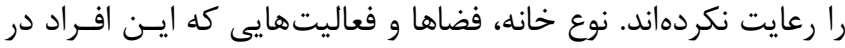

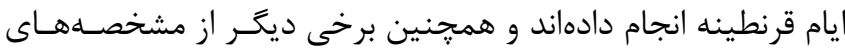

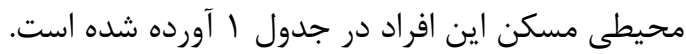

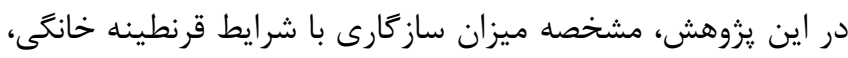

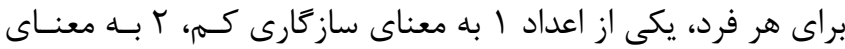

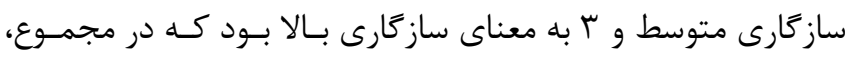

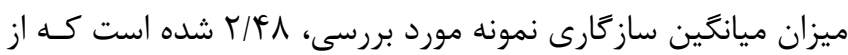

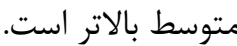


يعنى هرجه ساكنان از ياسخَكويى مسكن خود بــه شـرايط قرنطينـهـ راضىتر باشند، راحتتر توانستهاند با خانهنشينى طولانىمدت كنـار

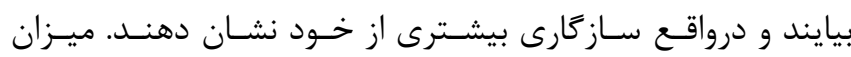

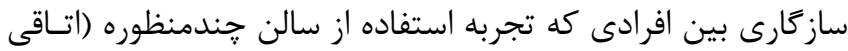

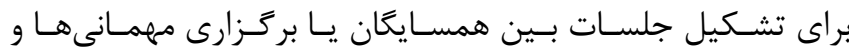

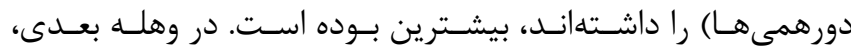

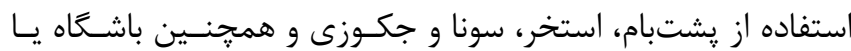

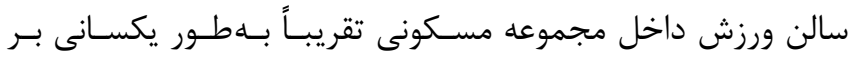

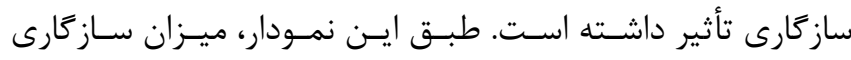

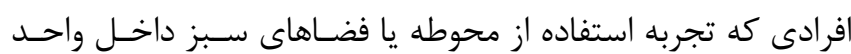
مسكونى، حياط خصوصى خود واحد و راهرو و لابى جهت صحبت و

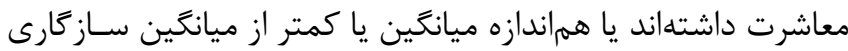

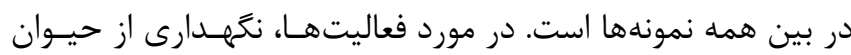
خانكَى، باغبانى يا رسيدگى به گل و زياه، خلوت با خود يـا مطالعـهـ در خانه، رسيدگى به امور خانه ازجمله تميزكارى يـا تعميــات و و ....

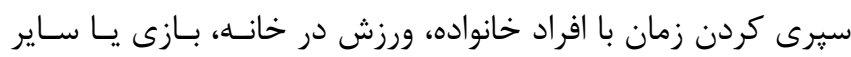

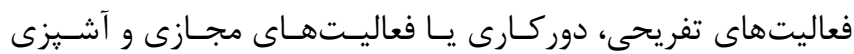

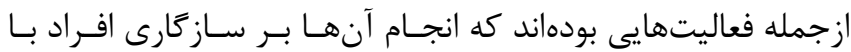

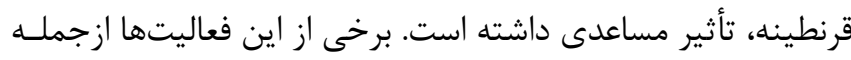
باغبانى، دوركارى و ورزش نيازمند تامين فضاى كالبدى مناسبى نيز

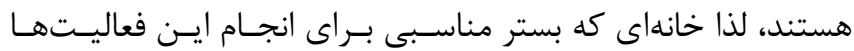
داشته است، مطلوبيت بيشترى داشته است. خانهاى كه تنوع رنگىى

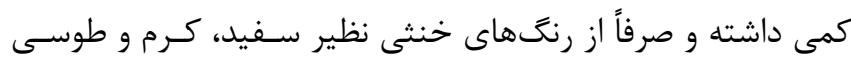

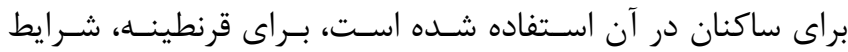

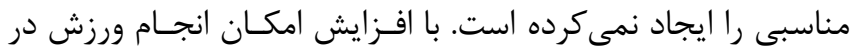

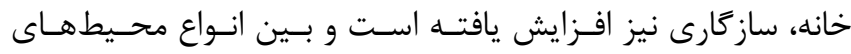

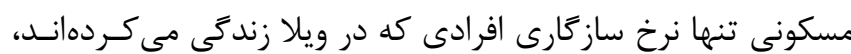
بيشتر از ميانگين بوده است. به نظر مىرسد زندگى در در برج، احتى احتمالاً

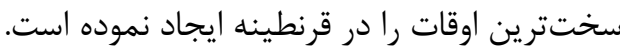

هم بودن اعضاى خانواده، خوابيدن و بازى كــــن مـورد توجـهـ قـرار كرفته است. براى اولويتسنجى مشخصـهـهـاى محيطى مسـكن در ارتباط با بحث ساز كارى، از 》درخت تصميهم گيرى" استفاده شد. بــه

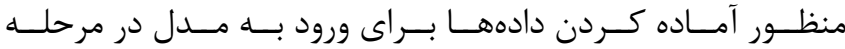
يِيشيردازش، نمونههايى كه به كمتر از • V درصد سـؤالات، جـواب

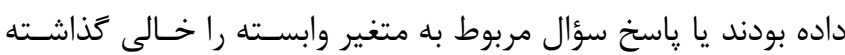

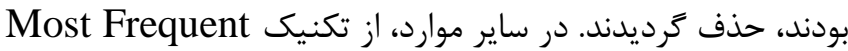
براى ير كردن مقادير گمشده استفاده شد. همجنـين بـراى ارزيـابى كارايى مدل، سبو نمونهاى كه بعد از ييش يردازش باقى مانى مانده بودند

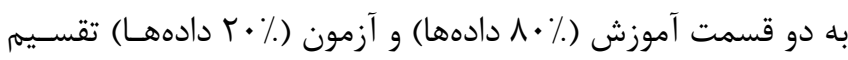

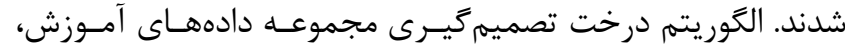

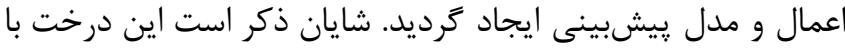

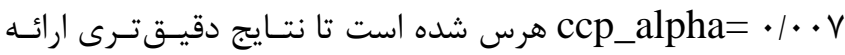
دهد. درنهايت درختى با D T مشخصه، وF ب ا ايجاد شد كه ץ رديف اول كه نشاندهنده مهرمترين مؤلفـهـــاى شرايط محيطى مسكن در ارتباط با ساز گارى افراد هستند ( نمـودار

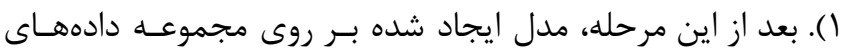

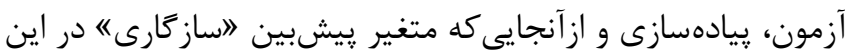

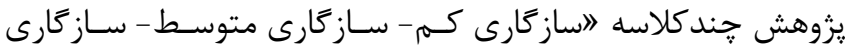

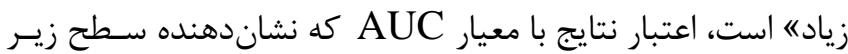

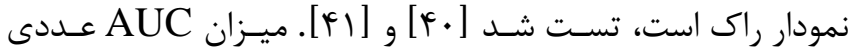
بين • تا ا است كه عـدد ه| • نشـاندهنـده تصـادفى عمـل كـردن درخت تصميم گيرى و درنتيجه بـى اعتبـار بـودن آن اســ، ايسن در

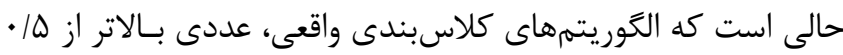
دارند [Fr]. مقدار AUC براى مدل درخت تصميهم

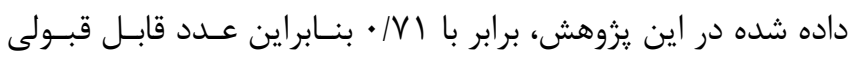

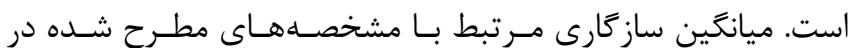
درخت تصميم، در نمودار r ارائسه شـده اسـت. ميـزان رضـايتمندى سكونتى و سازگًارى با شرايط قرنطينه ارتباط همسـويى داشـتـانـدـ 
سال بيستم، شماره ششم، آذر ـدى .. If

جدول ا: مشخصه هاى توصيفى وضعيت افراد ياسخدهنده در دوران قرنطينه

\begin{tabular}{|c|c|c|c|}
\hline درصد فراوانى & مشخصه & & رديف \\
\hline$\% \pi \cdot / 1$ & ويلايى & \multirow{4}{*}{ نوع خانه دوران قرنطينه } & \multirow{4}{*}{1} \\
\hline$\% . \Delta 1 / f$ & تك آيارتمان حندطبقه & & \\
\hline$\% 19 / 1$ & برج & & \\
\hline$\% / T$ & 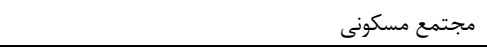 & & \\
\hline$\% / \Delta r / 9$ & حياط خصوصى خود واحد مسكونى & \multirow{7}{*}{ فضاهاى استفاده شده در دوران قرنطينه خانكى } & \multirow{7}{*}{ r } \\
\hline$\% T Y / V$ & يشتبام & & \\
\hline$\% \cdot r \cdot / V$ & محوطه و يا فضاهاى سبز داخل مجموعه مسكونى & & \\
\hline$\% / r \cdot / V$ & 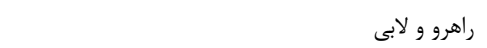 & & \\
\hline$\% 1 \cdot / 4$ & سالن حندمنظوره (اتاق جلسات، مهمانى و دورهمى و...) & & \\
\hline$\% 1 / \mathrm{V}$ & استخر،سونا و جكوزى داخل محيط سكونتى & & \\
\hline$\% 1 / \Delta$ & باشكاه داخل محيط سكونتى & & \\
\hline$\% \vee r / V$ & فيلم ديدن & \multirow{10}{*}{ فعاليتهاى انجام شده در دوران قرنطينه خانكى } & \multirow{10}{*}{ r } \\
\hline$\% . \Delta 9 / r$ & خلوت با خود يا مطالعه در خانه & & \\
\hline$\% . \Delta 9 / 1$ & رسيدگى به امور خانه & & \\
\hline$\% \Delta \Delta / \Delta$ & سيرى كردن زمان با افراد خانواده & & \\
\hline$\% \Delta F / 9$ & آشيزى & & \\
\hline$\% \Delta F$ & دور كارى يا فعاليت آموزشى مجازى & & \\
\hline$\% \notin \leftarrow / 1$ & ويدئوكنفرانس با دوستان يا اقوام & & \\
\hline$\% \cdot r \cdot / \Lambda$ & ورزش و فعاليتهاى تفريحى - حركتى & & \\
\hline$\% \pi \cdot / 1$ & باغِهبانى يا رسيدگى به كَل و كَياه & & \\
\hline$\% \cdot \mathrm{N} / 9$ & نكمهدارى از حيوان خانكى & & \\
\hline$\% \pi r / 9$ & اصلاً & \multirow{3}{*}{ ميزان تنوع رنى خانه دوران قرنطينه } & \multirow{3}{*}{ f } \\
\hline$\% .9 Y / \cdot$ & 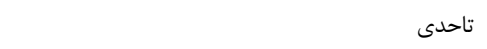 & & \\
\hline$\% 14 / 1$ & 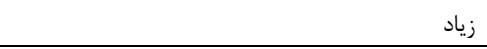 & & \\
\hline$\% \vee \vee \Lambda / r$ & رنغ رهاى خنثى مثل سفيد -كرم -طوسى & \multirow{3}{*}{ رنغ غالب خانه دوران قرنطينه } & \multirow{3}{*}{$\Delta$} \\
\hline$\% 1 r / r$ & رنغ رهاى سرد مثل آبى، سبز، ياسى & & \\
\hline$\% 1 \% / 9$ & رنَّهاى گرم مثل قرمز، زرد و نارنجى & & \\
\hline$\% / r \Delta / r$ & اصلاً & \multirow{3}{*}{ امكان انجام ورزش در خانه در دوران قرنطينه } & \multirow{3}{*}{4} \\
\hline$\% / \Delta F / T$ & 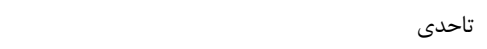 & & \\
\hline$\% / r \cdot / 4$ & 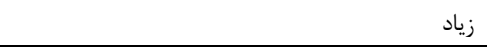 & & \\
\hline$\% 1 \cdot 11$ & اصلاً & \multirow{3}{*}{ رايام قرنطينه } & \multirow{3}{*}{$v$} \\
\hline$\% / \Delta r / V$ & 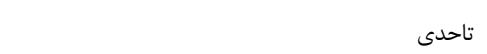 & & \\
\hline 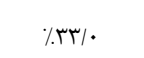 & 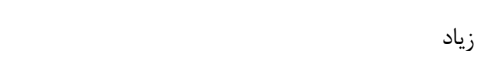 & & \\
\hline
\end{tabular}

جدول r: فراوانى و درصد فراوانى فضاهاى مسكونى تغييريافته در دوران قرنطينه

\begin{tabular}{|c|c|c|c|c|c|c|c|c|c|c|}
\hline هيجيك از فضاها & ساير فضاها & ناهارخورى & آشيزخانه & سرويس بهداشتى & ورودى & بالكن & نشيمن & يذيرايى & اتاقخواب & فضا \\
\hline rAr & $\Delta$ & r & r & $\Delta$ & $\wedge$ & 11 & IV & $4 q$ & vi & فراوانى \\
\hline$\% .95 / 19$ & $\% 1 /$. & $\% \cdot /$ AV & $\% \cdot /$ AV & $\% 1 / \cdot 9$ & $\% 1 / V \Delta$ & $\% / r / F i$ & $\% / \mathrm{V}$ & $\% 1 \cdot / V$ & $\% \mid \Delta / 9$ & درصد فراوانى \\
\hline
\end{tabular}


سال بيستم، شماره ششم، آذر -دى .. If

نشريه يزوهشكده علوم بهداشتى جهاددانشاهى

رضايتمندى از ميزان مناسب بودن خانه ايام قرنطينه در باسخكويى به نيازها و شرايط خاص ايام قرنطينه

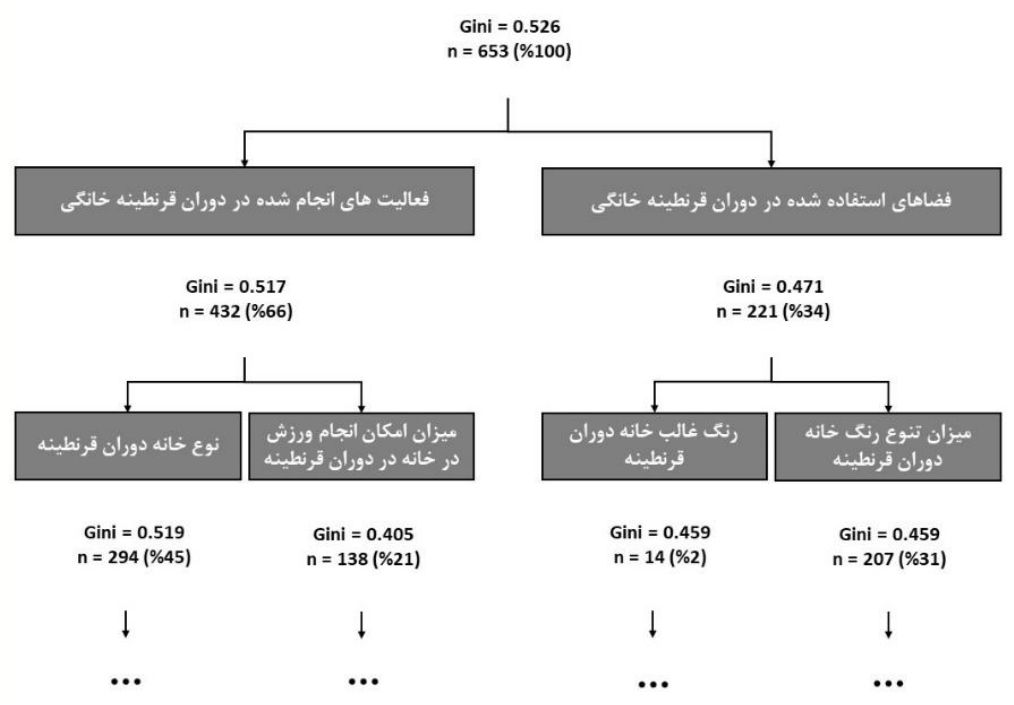

نمودار ا: بخشى از مدل درخت تصميمَيرى آموزش ديده شده 


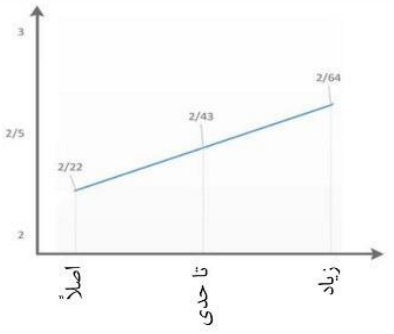

ميزان سازكارى در ارتباط با فضاهاى مشاع استفاده شده در دوران قرنطينه ميزان سازكارى در ارتباط با فعاليت هاى انجام شده در دوران قرنطينه
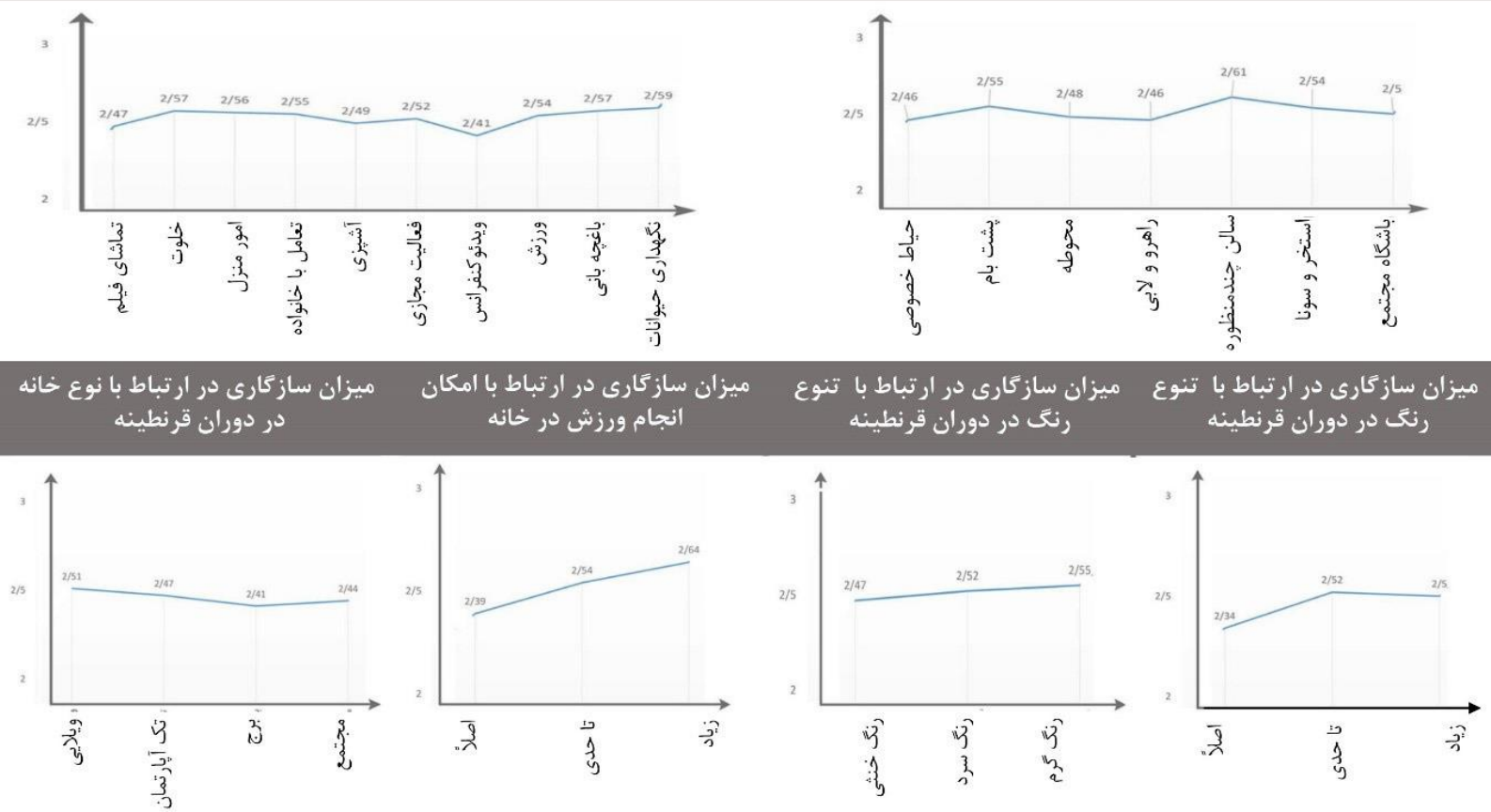

نمودار ז: ميانكَين سازكًارى در ارتباط با مشخصه هاى محيطى مسكن

مذكور را داشتهاند، نسبت به ساير افراد، زياد نيست. درعين حال بــهـ نظر مى رسد مجموعههاى سـكونتى مجهزتـر، كيفيـت بـالاترى نيـز

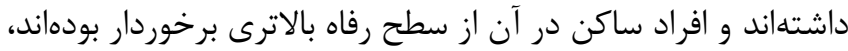
لذا عوامل ينهان زيادى را مىتوان در سطح سازگًارى دخيل دانست.

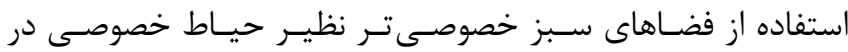

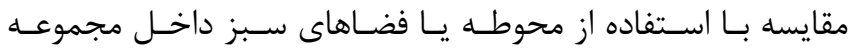

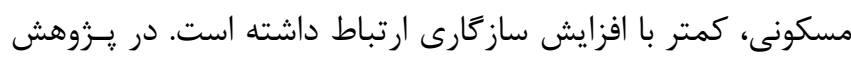

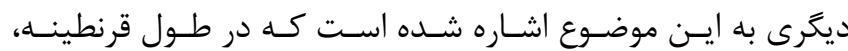
فضاهاى باز خصوصى، ارتباط منفى با رفاه ذهنى ساكنان داشتهانـد،

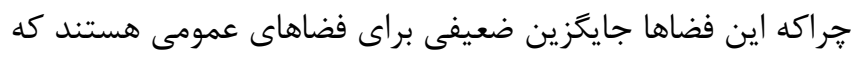

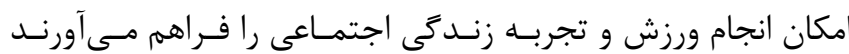

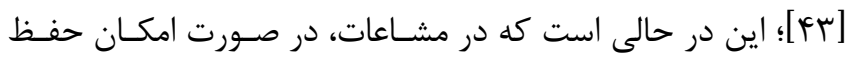

مجموعــاى از عوامـلـ ذهنــى و عينــى در كنــار هـــم موجبــات رضايتمندى ساكنان را فراهم كرده و بدان ماهيتى جامع مىبخشند؛

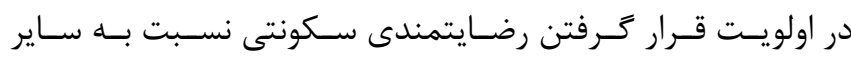
مشخصهها در درخت تصميمزيرى، شايد به علـت همـين جـامعتـر

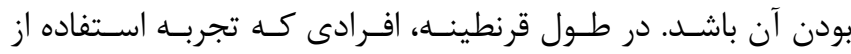

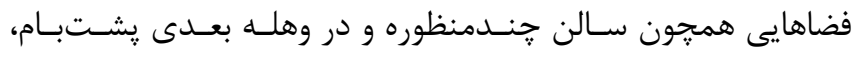

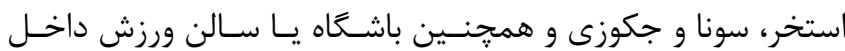
مجموعه مسكونى را داشـتهانـد، سـازگًارى بيشـترى از خـود نشـان

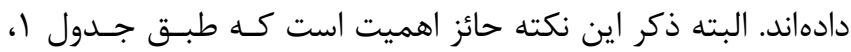

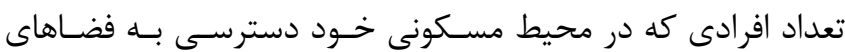


انجام دوركارى، تشكيل كلاسها و حتسى جلسـات مجـازى ادارى و دوستانه، آمادهسازى مى شدند. با توجه به اينكه همه افـراد خـان جانواده

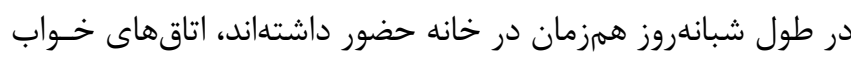

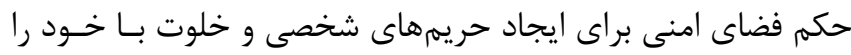

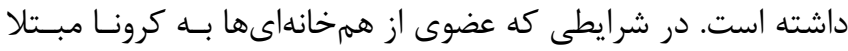

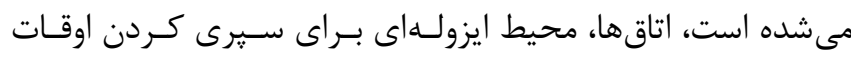

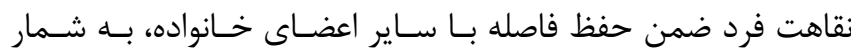

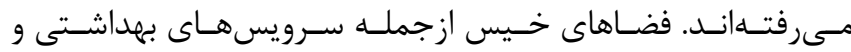
آشيزخانه براى جلوكيرى از سرايت بيمارى مههمترين فضا بـودهانــد،

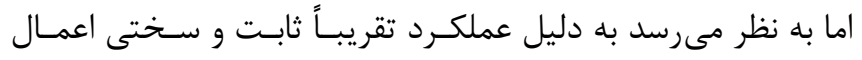
تغييرات در اين فضاها، كمترين دست كارى را داشتهاند.

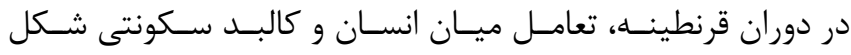

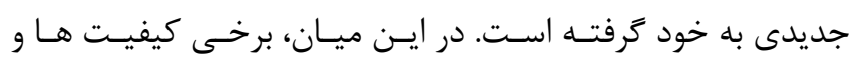

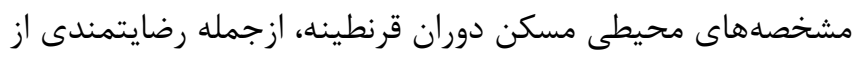

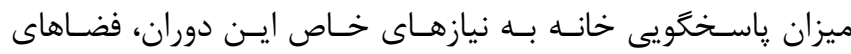

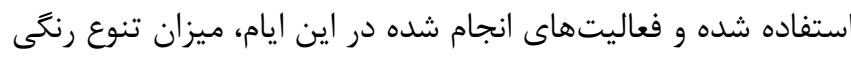
و رنغ غالب خانه، ميزان امكان انجام ورزش و نوع خانه، بـه ترتيسب

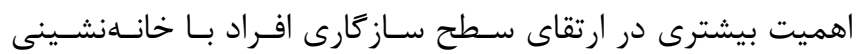

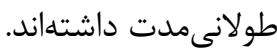

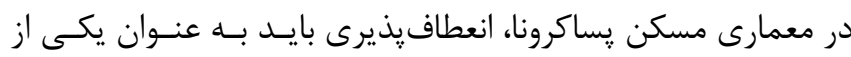
مههمترين راهبردهاى طراحى لحاظ شود خرا كه فضـاهاى سـكونتى

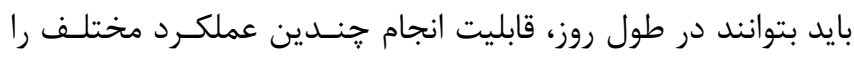

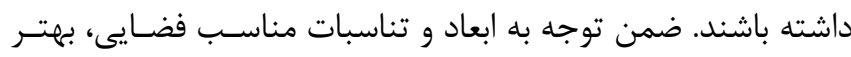

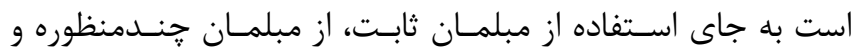

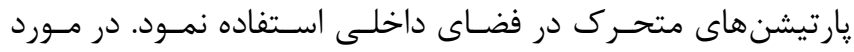

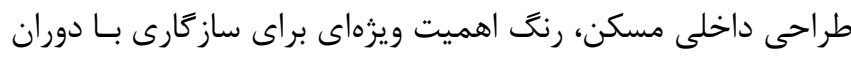

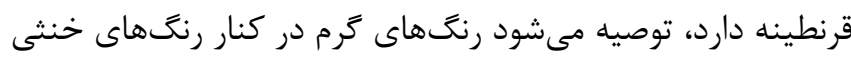

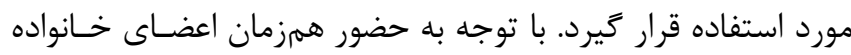

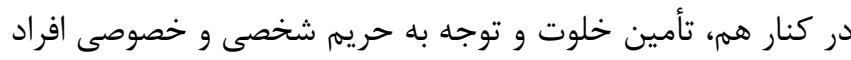

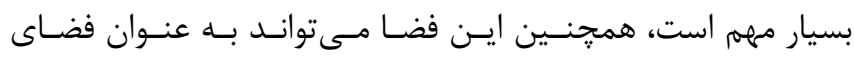
قرنطينه فرد بيمار همم استفاده شود. براى دوركارى، آموزش مجـازى إسى و دورهمىهاى مجازى، وجود فضايى كه از لحاظ نور، تهويه، شرايط

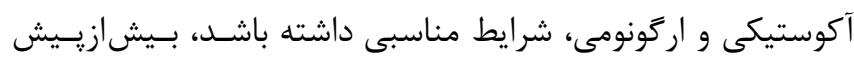
احساس مىشود. از سوى ديكر در دوران قرنطينه، كيفيت مشـاعات

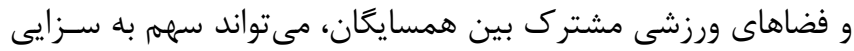

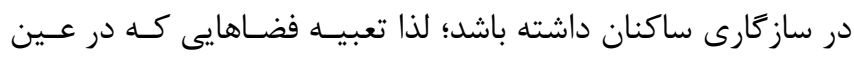

فاصله اجتماعى، امكان تعاملات اجتماعى بيشترى وجود دارد [FF].

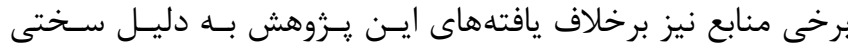

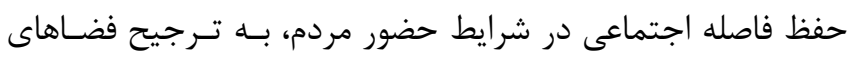

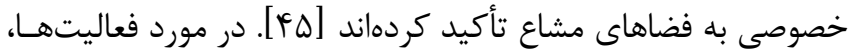

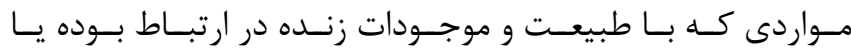

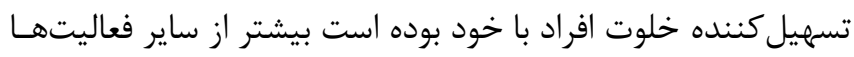

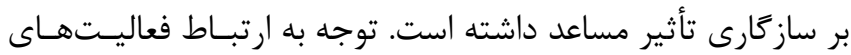

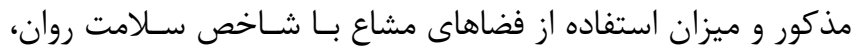

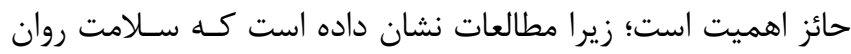

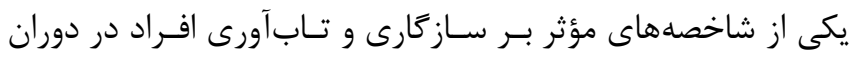

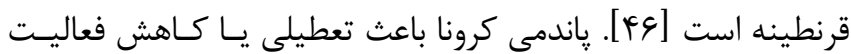

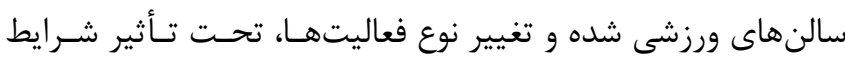

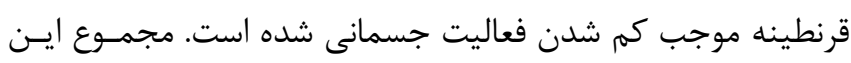

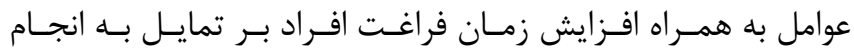

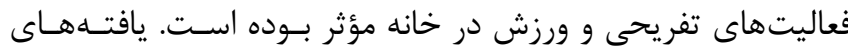

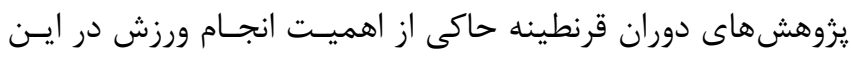

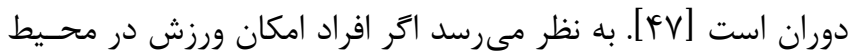

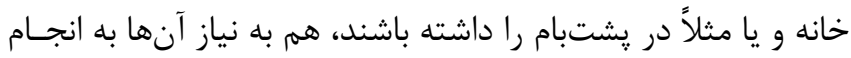

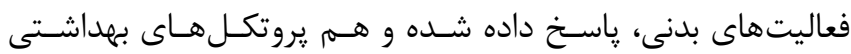

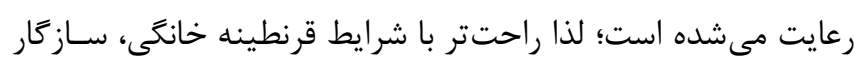
شدهاند. رنگ از ديخر مشخصههاى محيطى مرتبط با بحث سازكارى آنى

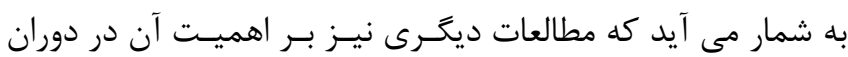

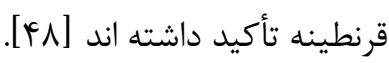
در اين يزوهش تلاش شد وجوهى از كالبد مسكن كه بـر سـازكارى افراد با خانهنشينى طولانىمدت اثركذار است، شناسايى شـود. ابتــدا

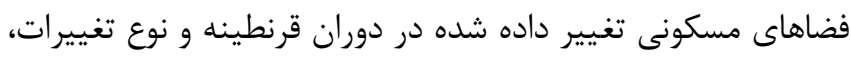

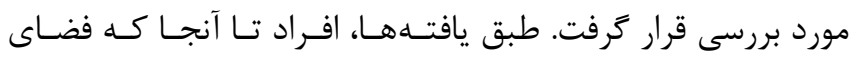

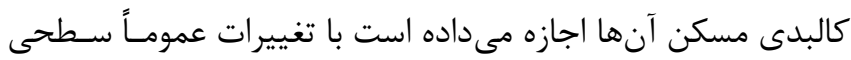

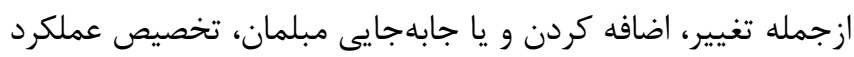

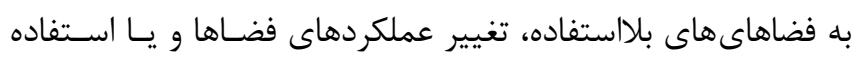
جندمنظوره از آنها، ايـن فضـاها را بــراى شــايط دوران قرنطينـها،

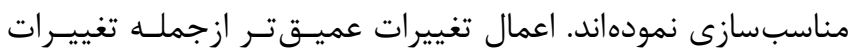

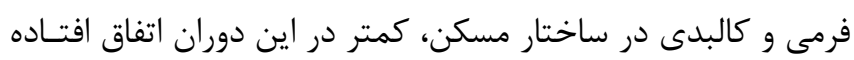
است. در ميان فضاهاى مسكونى، اتاقهاى خواب بيشترين تغييـرات

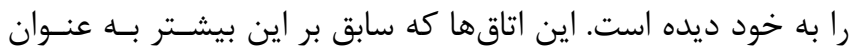

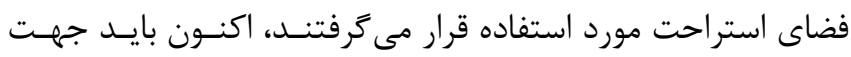




$$
\begin{aligned}
& \text { سهم نويسند } \\
& \text { سيده فرشته احسانى اسكويى: طراحسى و اجـراى مطالعـه و نعَـارش } \\
& \text { مقاله } \\
& \text { زينت امينىفر: دانشجو، طراحى و اجراى مطالعه و نعارش مقاله }
\end{aligned}
$$

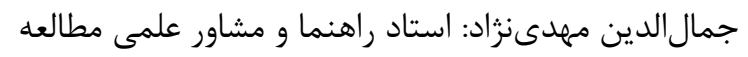

$$
\begin{aligned}
& \text { حميدرضا عظمتى: استاد راهنما و مشاور علمى مطالعه }
\end{aligned}
$$

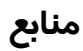

1. World Health Organization. Statement on the Second Meeting of the Emergency Committee of the International Health Regulations (2005) about Outbreak of the New Coronavirus (2019-nCoV), 2020 January 30; [Available online: https://www.who.int/news/item/30-01-2020-statement-on-thesecond-meeting-of-the-international-health-regulations-(2005)emergency-committee-regarding-the-outbreak-of-novelcoronavirus-(2019-ncov) (accessed on 20 March 2021)]

2. Lipsitch M, Swerdlow DL, Finelli L. Defining the Epidemiology of Covid-19 Studies Needed. New England Journal of Medicine 2020;382:1194-1196

3. Ghorbani R. COVID-19 Pandemic and Family Physician in Iran. Faculty of Management and Medical Information 2020;2:57-58 [Persian]

4. Fezi B. A. Health Engaged Architecture in the Context of COVID-19. Journal of Green Building 2020;15:185-212

5. Amerio A, Brambilla A, Morganti A, Aguglia A, Bianchi D, Santi F, Costantini L, Odone A, Costanza A, Signorelli C, Serafini G. COVID-19 Lockdown: Housing Built Environment's Effects on Mental Health. International Journal of Environmental Research and Public Health 2020;17:5973

6. Hubbard G, Daas CD, Johnston M, Murchie P, Thompson CW, Dixon D. Are Rurality, Area Deprivation, Access to Outside Space, and Green Space Associated with Mental Health during the COVID-19 Pandemic? A Cross Sectional Study (CHARIS-E). International Journal of Environmental Research and Public Health 2021;18:3869

7. Muggah R. Urban Governance: Cities in a Time of COVID-19 Challenges and Opportunities in the Post-COVID-19 World, World Economic Forum 2020 May 19; [Available online: https://www.weforum.org/reports/post-covid-19-challengesand-opportunities (accessed on 10 March 2021)]

8. Kenworthy JR. The Eco-City: Ten Key Transport and Planning Dimensions for Sustainable

$$
\begin{aligned}
& \text { حفظ ارتباطات اجتماعى، فواصل بين فـردى را تــأمين مسىكنـــد و }
\end{aligned}
$$

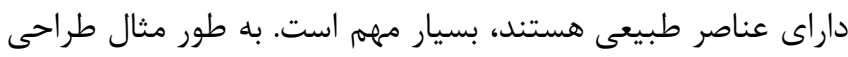

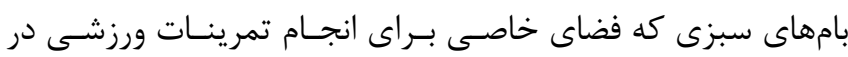

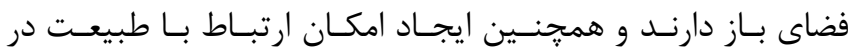

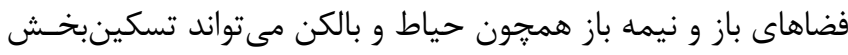

$$
\begin{aligned}
& \text { شرايط سخت افراد در دوران قرنطينه باشد. }
\end{aligned}
$$

City Development. Environment and Urbanization 2006; 18:67-85

9. Vittori G, Guenther R. Sustainable Healthcare Architecture, $2^{\text {th }}$ Edition; John Wiley \& Sons: Hoboken, New Jersey, 2013; ISSN: 2631-6862

10. Bettaieb DM, Alsabban R. Emerging Living Styles Post-COVID-19: Housing Flexibility as a Fundamental Requirement for Apartments in Jeddah. Archnet-IJAR, International Journal of Architectural Research 2021;15:2631-6862

11. Francisco R, Pedro M, Delvecchio E, Espada JP, Morales A, Mazzeschi C, Orgilés M. Psychological Symptoms and Behavioral Changes in Children and Adolescents During The Early Phase of COVID-19 Quarantine in Three European Countries. Frontiers in Psychiatry 2020;11:1329

12. Alonso $M$, Rubio A, Escrig $T$, Soto $T$, Serrano-Lanzarote B, Matarredona-Desantes N. Identification of Measures to Strengthen Resilience in Houses on the Basis of Lockdown Experience during COVID-19. Sustainability 2021;13:6168

13. Duque-Calvache R, Torrado JM, \& MesaPedrazas Á. Lockdown and Adaptation: Residential Mobility in Spain during the COVID-19 Crisis. European Societies 2020;23:1-18

14. Cuerdo-Vilches T, Navas-Martín MÁ, Oteiza I. A Mixed Approach on Resilience of Spanish Dwellings and Households during COVID-19 Lockdown. Sustainability 2020;12:10198

15. Daniela DA, Gola M, Letizia A, Marco D, Fara GM, Rebecchi A, Gaetano S, Capolongo S. COVID-19 and Living Spaces challenge. Well-being and Public Health Recommendations for a Healthy, Safe, and Sustainable Housing. Acta Biomedica 2020;91:61-75

16. Amerio A, Brambilla A, Morganti A, Aguglia A, Bianchi D, Santi F, Costantini L, Odone A, Costanza A, Signorelli C, Serafini G. COVID-19 Lockdown: Housing Built Environment's Effects on 
Mental Health. International Journal of Environmental Research and Public Health 2020;17:5973

17. Pouso S, Borja A, Fleming LE, GómezBaggethun E, White MP, Uyarra MC. Maintaining Contact with Blue-Green Spaces during The COVID19 Pandemic Associated with Positive Mental Health. Science of the Total Environment 2020;20:143984

18. Zarrabi M, Yazdanfar SA, Hosseini SB. COVID-19 and Healthy Home Preferences: The Case of Apartment Residents in Tehran. Journal of Building Engineering. 2021;35:102021

19. Adediran A, Oladejo SO, Akinwande TO, Ajibade SS, Moveh S. Housing Quality Standard and Covid-19 Pandemic: A Call for Attention in Nigeria. Journal of Science, Engineering, Technology and Management 2020;2:1-10

20. Bereitschaft B, Scheller D. How Might the COVID-19 Pandemic Affect 21 ${ }^{\text {st }}$ Century Urban Design, Planning, and Development? Urban Science 2020;4:56-78

21. Hubbard G, Daas CD, Johnston M, Murchie P, Thompson CW, Dixon D. Are Rurality, Area Deprivation, Access to Outside Space, and Green Space Associated with Mental Health during the COVID-19 Pandemic? A Cross Sectional Study (CHARIS-E). International Journal of Environmental Research and Public Health 2021;18:3869

22. Wilson EO, Biophilia, 12th ed; Harvard University Press: Cambridge, MA: UK, 2003

23. Tokazhanov G, Tleuken A, Guney M, Turkyilmaz A, Karaca F. How Is COVID-19 Experience Transforming Sustainability Requirements of Residential Buildings? A Review. Sustainability 2020; $12: 8732$

24. Alonso $M$, Rubio A, Escrig $\mathrm{T}$, Soto $\mathrm{T}$, Serrano-Lanzarote B, Matarredona-Desantes N. Identification of Measures to Strengthen Resilience in Houses on the Basis of Lockdown Experience during COVID-19. Sustainability 2021;13:6168

25. Cuerdo-Vilches T, Navas-Martín MA, and Oteiza I. A Mixed Approach on Resilience of Spanish Dwellings and Households during Covid-19 Lockdown. Sustainability 2020;12:1-24

26. Putra ID. "Stay at home" for addressing COVID-19 protocol: learning from the traditional Balinese house. Archnet-IJAR: International Journal of Architectural Research 2020;15:64-78

27. Mohareb N. Has an Urban 'New Normal' Become Necessary Following the Corona Pandemic? Architecture And Planning Journal 2020;26:5
28. Spennemann D. H. Residential Architecture in a Post-Pandemic World: Implications of COVID-19 for New Construction and for Adapting Heritage Buildings. Journal of Green Building 2021;16:199-215 29. Daszak P, Amuasi J, das Neves C.G,Hayman, D, Kuiken T, Roche B, Zambrana-Torrelio C, Buss P, Dundarova H, Feferholtz Y, et al. Workshop Report on Biodiversity and Pandemics of the Intergovernmental Platform on Biodiversity and Ecosystem Ser-vices. The Intergovernmental SciencePolicy Platform on Biodiversity and Ecosystem Services (IPBES) 2020; [Available online:https://ipbes.net/sites/default/files/202012/IPBES\%2 0Workshop\%20on\%20Biodiversity\%20and\%20

Pandemics\%20Report_0.pdf (accessed on 30 March 2021)] 30. Heidari Abdi A. The Relationship Between Adjustment Dimensions, The Quality of Interpersonal Relationships and Its Comparison in Successful and Unsuccessful University Students, Fundamentals of Mental Health 2016;18:577-581

31. Zabetian E, Kheiuldin R. Assessment Hierarchy Model of the Relationship between Psychological Adaptation for Achieving Thermal Comfort and Sense of Place in Urban Spaces, Motaleate Shahri 2018;7:79-90 [Persian]

32. Ghiasabadi Farahani E, Jafari Harandi R. Predict Cognitive Flexibility through Social Adjustment and Responsibility among Female Students. Quarterly Social Psychology Research 2021;10:135-50 [Persian]

33. Nikolopoulou M. The Effect of Climate on the Use of Open Spaces In The Urban Environment: Relation to Tourism. Report of a Workshop Held at Porto Carras, Neos Marmaras, Halkidiki, Greece, 5-10 October 2001[Available online: https://www.researchgate.net/publication/233758777_Proce edings_of_the_First_International_Workshopon_Climate_T ourism_and_Recreation(accessed on 26 March 2021)]

34. Malik J, Bardhan R, Hong T, Piette MA. Contextualising Adaptive Comfort Behaviour within Low-Income Housing of Mumbai, India. Building and Environment 2020;177:106877

35. T,ălnar-Naghi DI. Research Note: Job Satisfaction and Working from House in Romania, before and during COVID-19. Calitatea vieţii 2021;32: $1-22$

36. Kumar, P. R., Ravi, V. Bankruptcy Prediction in Banks and Firms via Statistical and Intelligent Techniques-A Review. European Journal of Operational Research 2007;180:1-28 
37. Murphy KP. Machine Learning: A Probabilistic Perspective. $1^{\text {st }}$ Edition, MIT press: Cambridge, London, 2012

38. Michie D, Spiegelhalter DJ, Taylor CC. Machine learning, neural and statistical classification, 2nd Edition; Ellis Horwood Ltd: UK, 1994

39. Kazemitabar SJ, Amini AA, Bloniarz A, Talwalkar A. Variable importance using decision trees. InProceedings of the $31^{\text {st }}$ International Conference on Neural Information Processing Systems 2017 Dec 4; [Available online: https://www.cs.cmu.edu/ atalwalk/dstump_nips17.pdf (accessed on 20 December 2021)]

40. Bradley AP. The Use of The Area Under The ROC Curve in The Evaluation of Machine Learning Algorithms. Pattern Recognition 1997;30:1145-1159

41. Hanley JA, McNeil BJ. The Meaning and Use of the Area under a Receiver Operating Characteristic (ROC) Curve. Radiology 1982;143:29-36

42. Fawcett T. An Introduction to ROC Analysis. Pattern Recognition Letters 2006;27:861-874

43. Zhuo K, Zacharias J. The Impact of Out-ofHome Leisure before Quarantine and Domestic Leisure during Quarantine on Subjective Well-Being. Leisure Studies 2021;40:321-37
44. Pan SL, Cui M, Qian J. Information Resource Orchestration during the COVID-19 Pandemic: A Study of Community Lockdowns in China. International Journal of Information Management 2020;54:102143

45. Pouso S, Borja A, Fleming LE, GómezBaggethun E, White MP, Uyarra MC. Maintaining Contact with Blue-Green Spaces during the COVID19 Pandemic Associated with Positive Mental Health. Science of the Total Environment 2020;20:143984

46. Tokazhanov G, Tleuken A, Durdyev S, Otesh N, Guney M, Turkyilmaz A, Karaca F. Stakeholder based Weights of New Sustainability Indicators Providing Pandemic Resilience for Residential Buildings. Sustainable Cities and Society 2021;75:103300

47. Cuerdo-Vilches T, Navas-Martín MÁ, Oteiza I. A Mixed Approach on Resilience of Spanish Dwellings and Households during COVID-19 Lockdown. Sustainability 2020;12:10198

48. Aljunaidy MM, Adi MN. The Psychological Impact of COVID-19 Quarantine on Children, and the Role of Parental Support and Physical Environment Design. Discover Psychology 2021;1:1-1 